\title{
Novel methods in psychiatric epidemiology
}

\author{
Ulrich Reininghaus $^{1,2} \cdot$ Katherine M. Keyes ${ }^{3}$ Craig Morgan ${ }^{2,4}$
}

Published online: 22 June 2016

(c) Springer-Verlag Berlin Heidelberg 2016

In January 2014, SPPE began to publish a series of reviews, editorials, and commentaries with the goal of synthesising evidence and providing a platform for discussing and advancing the state of the art in social psychiatry and psychiatric epidemiology. More than 2 years into these series, it is useful to take stock, look back, and provide an overview of what comes next.

The series set off to synthesise and discuss evidence on the biological and psychological mechanisms through which social contexts and experiences increase risk of adverse mental health outcomes [1,2], reflecting the recent shift in theoretical and measurement foundations towards integrated models of aetiology. This included reviews and commentaries on gene-environment interactions [3-6] and on epigenetic $[7,8]$, inflammatory $[9,10]$, cognitive, affective [11-13], and neurobiological mechanisms [14] through which stress, adversity, and other key socio-environmental exposures may affect mental health. These

Ulrich Reininghaus

u.reininghaus@maastrichtuniversity.nl

1 Department of Psychiatry and Psychology, School for Mental Health and Neuroscience, Faculty of Health, Medicine and Life Sciences, Maastricht University, P.O. Box 616 (VIJV1), 6200 MD Maastricht, The Netherlands

2 Centre for Epidemiology and Public Health, Health Service and Population Research Department, Institute of Psychiatry, Psychology and Neuroscience, King's College London, London, UK

3 Department of Epidemiology, Mailman School of Public Health, Columbia University, New York, NY, USA

4 National Institute for Health Research (NIHR) Mental Health Biomedical Research Centre (BRC) at South London and Maudsley NHS Foundation Trust and King's College London, London, UK reviews and commentaries highlight the rapid technological and subsequent scientific advances in psychiatry in uncovering mechanisms that underlie the epidemiological associations between adversity and illness that have been documented, since the advent of psychiatric epidemiology, yet also reveal a paradigm shift in its beginning stages of formation. In view of recent and impending revisions of the Diagnostic and Statistical Manual of Mental Disorders and International Classification of Diseases as well as movements towards non-binary classifications of psychiatric phenomena, the series then addressed current challenges in diagnostic classification in psychiatry [15-19], reviewing the enduring challenge of high comorbidity rates [19], methodological considerations in the use of latent variable models of psychopathology [16], and the evidence on transdiagnostic factors $[17,18]$ that may underlie individual common mental disorders $[17,18]$, personality disorders [18], and psychotic disorders [18, 20-22]. This was followed by reviews pulling together and discussing key findings from major epidemiological studies in the context of new challenges in the field and directions for future research [23-30]. It is abundantly clear, particularly from large-scale epidemiological studies, that the origins of most mental health problems trace back to childhood and adolescence [1] and the series continued with reviews and commentaries on youth mental health [31-36], including key findings from developmental epidemiology [32-34], protective and promotive factors [31], and the ongoing youth mental health reform in several countries $[35,36]$.

These reviews and commentaries testify to the continued value and vigour of social epidemiological research in mental health. However, there are of course challenges that remain to be addressed. The rapid advances in design, measurement, and statistics are often difficult to convey to a wider research audience and considered in isolation 
despite their overlap. One example of the latter are accelerated longitudinal designs, which, through developments in multilevel and growth mixture modelling, can now be more readily applied in psychiatric epidemiology [37]. Furthermore, as Keyes and Susser [1] note, debates about measurement are non-trivial given their implications not only for researchers but for all stakeholders. Therefore, what comes next in the SPPE series is an overview of recent advances in design, measurement, and statistics relevant to social psychiatry and psychiatric epidemiology.

In this issue of SPPE, a decade of research into the use of Immersive Virtual Reality (VR) designs for investigating psychological mechanisms associated with the onset and maintenance of psychosis is synthesised [38] and discussed [39]. While there has been a long tradition of using routine data and harnessing case registers in psychiatric epidemiology, data resources now accumulate in larger volumes in electronic format; Stewart and Davis [40] will review the current status and emerging possibilities of such 'big data' in mental health research in the next issue of SPPE. The series will then continue with reviews of recent developments in the closely related area of e-health, in particular, the use of ecological and geographic momentary assessment for measuring moment-to-moment variation in socio-environmental exposures, mental health, and substance use outcomes [41-44], and for investigating causal criteria under real-world conditions [44]. Ecological and geographic momentary designs bring into focus statistical methods for modelling spatial variation, studying local contexts, and testing network models of the structure of psychopathology; these will be considered in subsequent issues. As the range of novel technologies for measuring socio-environmental exposures increases, both between and within individuals, across the life course and in combination with biological and psychological mechanisms, as illustrated in the previous parts of the series on youth mental health and on integrated models, this brings to the fore statistical approaches for testing how exposures combine, in a multitude of ways, to increase risk of mental disorders. The current part of the SPPE series will illustrate this by illuminating methods for joint effects of time-varying exposures and statistical tests of additive interaction including a newly proposed statistical measure of disparities at the intersection of multiply marginalized groups.

In providing a platform for researchers to explain and engage with the SPPE audience regarding these developments of novel methodologies, the goal of this part of the SPPE series of reviews and commentaries is to contribute to advancing what is at the very heart of research and forms the basis for generating new insights and moving forward the field of social psychiatry and psychiatric epidemiology.

Acknowledgments UR is supported by a Veni grant from the Netherlands Organisation for Scientific Research (Grant No. 451-13-
022). CM acknowledges financial support from the National Institute for Health Research (NIHR) Biomedical Research Centre for Mental Health at South London and Maudsley NHS Foundation Trust and King's College London. The views expressed are those of the authors and not necessarily those of the NHS, the NIHR, or the Department of Health.

\section{Compliance with ethical standards}

Conflict of interest None.

\section{References}

1. Keyes KM, Susser E (2014) The expanding scope of psychiatric epidemiology in the 21st century. Soc Psychiatry Psychiatr Epidemiol 49(10):1521-1524. doi:10.1007/s00127-014-0938-5

2. Reininghaus U, Morgan C (2014) Integrated models in psychiatry: the state of the art. Soc Psychiatry Psychiatr Epidemiol 49(1):1-2. doi:10.1007/s00127-013-0807-7

3. Iyegbe C, Campbell D, Butler A, Ajnakina O, Sham P (2014) The emerging molecular architecture of schizophrenia, polygenic risk scores and the clinical implications for GxE research. Soc Psychiatry Psychiatr Epidemiol 49(2):169-182. doi:10.1007/s00127014-0823-2

4. Uher R (2014) Gene-environment interactions in common mental disorders: an update and strategy for a genome-wide search. Soc Psychiatry Psychiatr Epidemiol 49(1):3-14. doi:10.1007/s00127013-0801-0

5. Belsky DW, Suppli NP, Israel S (2014) Gene-environment interaction research in psychiatric epidemiology: a framework and implications for study design. Soc Psychiatry Psychiatr Epidemiol 49(10):1525-1529. doi:10.1007/s00127-014-0954-5

6. Kirkbride JB (2014) The emerging molecular architecture of schizophrenia, polygenic risk scores and the clinical implications for $\mathrm{gXe}$ research. Soc Psychiatry Psychiatr Epidemiol 49(10):1531-1534. doi:10.1007/s00127-014-0961-6

7. Pishva E, Kenis G, van den Hove D, Lesch KP, Boks MP, van Os J, Rutten BP (2014) The epigenome and postnatal environmental influences in psychotic disorders. Soc Psychiatry Psychiatr Epidemiol 49(3):337-348. doi:10.1007/s00127-014-0831-2

8. Kundakovic M (2014) Postnatal risk environments, epigenetics, and psychosis: putting the pieces together. Soc Psychiatry Psychiatr Epidemiol 49(10):1535-1536. doi:10.1007/s00127-0140927-8

9. Baumeister D, Russell A, Pariante CM, Mondelli V (2014) Inflammatory biomarker profiles of mental disorders and their relation to clinical, social and lifestyle factors. Soc Psychiatry Psychiatr Epidemiol 49(6):841-849. doi:10.1007/s00127-014-0887-z

10. Uddin M, Diwadkar VA (2014) Inflammation and psychopathology: what we now know, and what we need to know. Soc Psychiatry Psychiatr Epidemiol 49(10):1537-1539. doi:10. 1007/s00127-014-0934-9

11. Bentall RP, de Sousa P, Varese F, Wickham S, Sitko K, Haarmans M, Read J (2014) From adversity to psychosis: pathways and mechanisms from specific adversities to specific symptoms. Soc Psychiatry Psychiatr Epidemiol 49(7):1011-1022. doi:10. 1007/s00127-014-0914-0

12. Freeman D, Garety P (2014) Advances in understanding and treating persecutory delusions: a review. Soc Psychiatry Psychiatr Epidemiol 49(8):1179-1189. doi:10.1007/s00127-014-0928-7

13. Beards S, Fisher HL (2014) The journey to psychosis: an exploration of specific psychological pathways. Soc Psychiatry Psychiatr Epidemiol 49(10):1541-1544. doi:10.1007/s00127014-0953-6 
14. Akdeniz C, Tost H, Meyer-Lindenberg A (2014) The neurobiology of social environmental risk for schizophrenia: an evolving research field. Soc Psychiatry Psychiatr Epidemiol 49(4):507-517. doi:10.1007/s00127-014-0858-4

15. Bebbington $P$ (2015) Categories, continua and the growth of psychiatric knowledge. Soc Psychiatry Psychiatr Epidemiol 50(4):507-510. doi:10.1007/s00127-015-1033-2

16. Bohnke JR, Croudace TJ (2015) Factors of psychological distress: clinical value, measurement substance, and methodological artefacts. Soc Psychiatry Psychiatr Epidemiol. doi:10.1007/ s00127-015-1022-5

17. Carragher N, Krueger RF, Eaton NR, Slade T (2015) Disorders without borders: current and future directions in the meta-structure of mental disorders. Soc Psychiatry Psychiatr Epidemiol 50(3):339-350. doi:10.1007/s00127-014-1004-Z

18. Eaton NR, Rodriguez-Seijas C, Carragher N, Krueger RF (2015) Transdiagnostic factors of psychopathology and substance use disorders: a review. Soc Psychiatry Psychiatr Epidemiol 50(2):171-182. doi:10.1007/s00127-014-1001-2

19. Goldberg D (2015) Psychopathology and classification in psychiatry. Soc Psychiatry Psychiatr Epidemiol 50(1):1-5. doi:10. 1007/s00127-014-0924-y

20. Reininghaus U, Bohnke JR, Hosang G, Farmer A, Burns T, McGuffin P, Bentall RP (2016) Evaluation of the validity and utility of a transdiagnostic psychosis dimension encompassing schizophrenia and bipolar disorder. Br J Psychiatry. doi:10.1192/ bjp.bp. 115.167882

21. Reininghaus U, Priebe S, Bentall RP (2013) Testing the psychopathology of psychosis: evidence for a general psychosis dimension. Schizophr Bull 39(4):884-895. doi:10.1093/schbul/sbr182

22. Shevlin M, McElroy E, Bentall RP, Reininghaus U, Murphy J (2016) The psychosis continuum: testing a bifactor model of psychosis in a general population sample. Schizophr Bull. doi:10. 1093/schbul/sbw067

23. Beesdo-Baum K, Knappe S, Asselmann E, Zimmermann P, Bruckl T, Hofler M, Behrendt S, Lieb R, Wittchen HU (2015) The 'Early Developmental Stages of Psychopathology (EDSP) study': a 20-year review of methods and findings. Soc Psychiatry Psychiatr Epidemiol 50(6):851-866. doi:10.1007/s00127-015-1062-x

24. Fergusson DM, Boden JM, Horwood LJ (2015) Psychosocial sequelae of cannabis use and implications for policy: findings from the Christchurch Health and Development Study. Soc Psychiatry Psychiatr Epidemiol 50(9):1317-1326. doi:10.1007/ s00127-015-1070-x

25. Harding S, Read UM, Molaodi OR, Cassidy A, Maynard MJ, Lenguerrand E, Astell-Burt T, Teyhan A, Whitrow M, Enayat ZE (2015) The determinants of young adult social well-being and health (DASH) study: diversity, psychosocial determinants and health. Soc Psychiatry Psychiatr Epidemiol 50(8):1173-1188. doi:10.1007/s00127-015-1047-9

26. Harper S, Towers-Evans H, MacCabe J (2015) The aetiology of schizophrenia: what have the Swedish Medical Registers taught us? Soc Psychiatry Psychiatr Epidemiol 50(10):1471-1479. doi:10.1007/s00127-015-1081-7

27. Hasin DS, Grant BF (2015) The national epidemiologic survey on alcohol and related conditions (NESARC) Waves 1 and 2: review and summary of findings. Soc Psychiatry Psychiatr Epidemiol 50(11):1609-1640. doi:10.1007/s00127-015-1088-0

28. Poulton R, Moffitt T, Silva P (2015) The Dunedin Multidisciplinary Health and Development Study: overview of the first 40 years, with an eye to the future. Soc Psychiatry Psychiatr Epidemiol. doi:10.1007/s00127-015-1048-8

29. Hall W (2015) Erratum to: challenges in minimizing the adverse effects of cannabis use after legalization. Soc Psychiatry Psychiatr Epidemiol 50(9):1327. doi:10.1007/s00127-015-1117-z
30. Hall W (2015) Challenges in minimizing the adverse effects of cannabis use after legalization. Soc Psychiatry Psychiatr Epidemiol 50(7):1013-1015. doi:10.1007/s00127-015-1067-5

31. Brumley LD, Jaffee SR (2016) Defining and distinguishing promotive and protective effects for childhood externalizing psychopathology: a systematic review. Soc Psychiatry Psychiatr Epidemiol. doi:10.1007/s00127-016-1228-1

32. Costello EJ, Copeland W, Angold A (2016) The Great Smoky Mountains Study: developmental epidemiology in the southeastern United States. Soc Psychiatry Psychiatr Epidemiol 51(5):639-646. doi:10.1007/s00127-015-1168-1

33. Laurens KR, Cullen AE (2016) Toward earlier identification and preventative intervention in schizophrenia: evidence from the London Child Health and Development Study. Soc Psychiatry Psychiatr Epidemiol 51(4):475-491. doi:10.1007/s00127-015-1151-x

34. Lewis G, Jones PB, Goodyer IM (2016) The ROOTS study: a 10 -year review of findings on adolescent depression, and recommendations for future longitudinal research. Soc Psychiatry Psychiatr Epidemiol 51(2):161-170. doi:10.1007/s00127-015-1150-y

35. Malla A, Iyer S, McGorry P, Cannon M, Coughlan H, Singh S, Jones P, Joober R (2016) From early intervention in psychosis to youth mental health reform: a review of the evolution and transformation of mental health services for young people. Soc Psychiatry Psychiatr Epidemiol 51(3):319-326. doi:10.1007/ s00127-015-1165-4

36. Yung AR (2016) Youth services: the need to integrate mental health, physical health and social care: commentary on Malla et al.: from early intervention in psychosis to youth mental health reform: a review of the evolution and transformation of mental health services for young people. Soc Psychiatry Psychiatr Epidemiol 51(3):327-329. doi:10.1007/s00127-016-1195-6

37. Galbraith S, Bowden J, Mander A (2014) Accelerated longitudinal designs: an overview of modelling, power, costs and handling missing data. Stat Methods Med Res. doi:10.1177/ 0962280214547150

38. Valmaggia L, Day F, Rus-Calafell M (2016) Using virtual reality to investigate psychological processes and mechanisms associated with the onset and maintenance of psychosis: a systematic review. Soc Psychiatry Psychiatr Epidemiol 51(7). doi:10.1007/ s00127-016-1245-0

39. Gayer-Anderson C (2016) The application of virtual reality technology to understanding psychosis. Commentary on Valmaggia et al. (2016): Using virtual reality to investigate psychological processes and mechanisms associated with the onset and maintenance of psychosis: a systematic review. Soc Psychiatry Psychiatr Epidemiol 51(7). doi:10.1007/s00127-016-1262-z

40. Stewart R, Davis K (2016) 'Big data' in mental health researchcurrent status and emerging possibilities. Soc Psychiatry Psychiatr Epidemiol; (in press)

41. Epstein DH, Tyburski M, Craig IM, Phillips KA, Jobes ML, Vahabzadeh M, Mezghanni M, Lin JL, Furr-Holden CD, Preston KL (2014) Real-time tracking of neighborhood surroundings and mood in urban drug misusers: application of a new method to study behavior in its geographical context. Drug Alcohol Depend 134:22-29. doi:10.1016/j.drugalcdep.2013.09.007

42. Myin-Germeys I, Oorschot M, Collip D, Lataster J, Delespaul P, van Os J (2009) Experience sampling research in psychopathology: opening the black box of daily life. Psychol Med 39(9):1533-1547. doi:10.1017/S0033291708004947

43. Shiffman S, Stone AA, Hufford MR (2008) Ecological momentary assessment. Ann Rev Clin Psychol 4:1-32

44. Reininghaus U, Depp CA, Myin-Germeys I (2016) Ecological interventionist causal models in psychosis: targeting psychological mechanisms in daily life. Schizophr Bull. doi:10.1093/ schbul/sbv193 